\title{
Transient Aortic Intramural Hematoma Complicating Transaortic Valve Replacement
}

\author{
Taylor Thomas, BS, Anil K. Poulose, MD, Kevin M. Harris, MD* \\ Minneapolis Heart Institute Foundation at Abbott Northwestern Hospital, Minneapolis, Minnesota, USA
}

\begin{abstract}
Acute aortic intramural hematoma, which is a variant of acute aortic syndromes, most frequently occurs spontaneously and typically is treated similar to classic aortic dissection. Here, we describe a case in which an iatrogenic aortic intramural hematoma occurs shortly after transaortic valve replacement. The patient was managed conservatively, and the hematoma quickly resolved as demonstrated by serial imaging.

Copyright $\odot 2016$ Science International Corp.
\end{abstract}

\section{Key Words}

Aortic intramural hematoma - Latrogenic injury • TAVR

\section{Introduction}

Complications after transcatheter aortic valve replacement (TAVR) occur in $9.3 \%$ of patients and involve the aorta in $1.8 \%$ of patients [1]. latrogenic aortic dissection has been reported after coronary [2] and cardiac surgical procedures [3]. Because TAVR is utilized primarily in patients with higher surgical risk, acute aortic injuries that occur following TAVR create uncertainty for the ideal management of these conditions.

\section{Case Presentation}

An 83-year-old woman presented with severe symptomatic aortic stenosis with New York Heart Association class III symptoms of congestive heart failure.

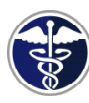

Fax +1 2037853552

E-Mail: aorta@scienceinternational.org

http://aorta.scienceinternational.org

\author{
(c) 2016 AORTA \\ Published by Science International Corp. \\ ISSN 2325-4637 \\ Accessible online at: \\ http://aorta.scienceinternational.org
}

Patient history was significant for cardiomyopathy (ejection fraction of 45-50\%) and coronary artery disease. As a frail, high-risk patient with a Society of Thoracic Surgeons score of 4.6 and combined morbidity/ mortality risk of $20.1 \%$, she was determined to be best suited for TAVR.

Preoperative computed tomography revealed normal aortic diameter and 2-3+ left ventricular outflow tract (LVOT) calcification. Transesophageal echocardiographic (TEE) images revealed an ascending aorta with a 3.5-cm diameter. A 26-mm SAPIEN 3 TAVR was implanted through a transfemoral artery approach using a 23-mm balloon for predilation, and this valve appeared well-seated. Immediately post-TAVR, intraoperative TEE showed development of an aortic intramural hematoma (IMH) with 9-10-mm crescentic thickening of the wall. This IMH extended from the aortic annulus to $2-3 \mathrm{~cm}$ above the valve (Figure $1 \mathrm{~A}$ and Video 1; see supplemental Video 1 at http:// dx.doi.org/10.12945/j.aorta.2016.16.029.vid.01) and was new based on preoperative imaging. Given the stability of the patient and her advanced age, aggressive management of her blood pressure and surveillance imaging were deemed the most appropriate treatment strategy. TEE performed the following day revealed that the IMH rim had markedly decreased to a maximum wall thickness of 3-4 $\mathrm{mm}$ (Figure 1B and Video 2; see supplemental Video 2 at http:// dx.doi.org/10.12945/j.aorta.2016.16.029.vid.02). Follow-up computed tomography angiography (CTA)

\footnotetext{
* Corresponding Author:

Kevin Harris, MD

Minneapolis Heart Institute Foundation at Abbott Northwestern Hospital 920 East 28th Street, Suite 300, Minneapolis, MN 55407, USA

Tel.: +1 612863 3900; Fax: +1 612863 5264; E-Mail: kevin.harris@allina.com
} 

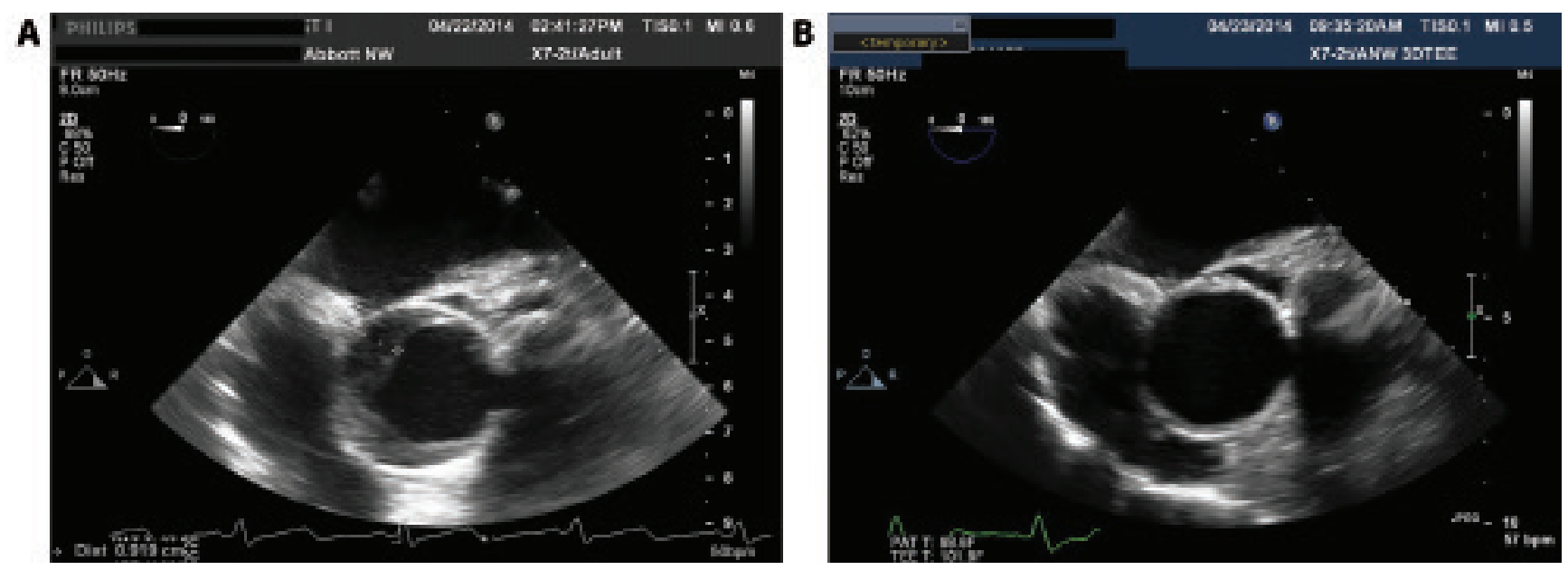

Figure 1. Transesophageal echo (TEE) image acquired immediately post-transcatheter aortic valve replacement (TAVR) indicates crescentic thickening of the ascending aortic wall consistent with intramural hematoma (Panel A). TEE image acquired on first day post-TAVR shows marked reduction in the degree of aortic wall thickening (Panel B).

performed 2 days post-TAVR confirmed an aortic IMH with wall thicknesses of $4 \mathrm{~mm}$ and $2 \mathrm{~mm}$ in the greater and lesser curvatures, respectively. This IMH extended up to the distal ascending aorta and was new compared with the pre-operative CT. It was considered stable compared to the TEE.

The patient was discharged 6 days post-TAVR. CTA performed 2 months post-TAVR revealed complete resolution of the IMH. The patient remained stable 12 months after discharge.

\section{Discussion}

This patient suffered an acute iatrogenic aortic injury related to a TAVR procedure. Prior to the advent of TAVR, risk factors for iatrogenic dissection included advanced age; history of atherosclerosis, diabetes, or systemic arterial hypertension; and prior coronary artery bypass surgery [3]. Patients with iatrogenic dissection related to cardiac surgical procedures generally have involvement of ascending aorta, absence of pain and the intramural hematoma variant of dissection [3]. Recent data for TAVR revealed that patients with LVOT calcification and aggressive annular oversizing may be at risk for aortic root rupture and peri-aortic hematomas [4], although it is uncertain whether risks for these aortic complications similarly predispose individuals to other forms of aortic injury. The patient in this case report had LVOT calcification that may have contributed to the aortic injury during annular expansion, although the valve was not oversized. A spectrum of aortic injuries can occur post-TAVR and include those contained to the aortic wall and those in the perioaortic space to rupture. In this case, the aortic injury was an $\mathrm{IMH}$, which is distinguished from a classic dissection via imaging by crescentic or circumferential thickening of the aortic wall related to bleeding within the wall without any evidence of an entry point or intimal flap [5].

The American College of Cardiology/American Heart Association aortic guidelines do not delineate different management strategies for dissection that is iatrogenic in etiology [6]. The European Society guidelines discuss iatrogenic catheter injuries, and although the management for these cases is not standardized, a conservative strategy is frequently applied [7]. These iatrogenic injuries related to percutaneous coronary procedures are frequently managed conservatively and may be sealed with stent placement in cases that originate in the coronary arteries [2]. Patients with iatrogenic aortic syndromes (dissection/ hematoma) have similar outcomes to patients with spontaneous dissections, including those who undergo surgical repair $[3,8]$. In general, spontaneous IMH is usually treated similarly to typical dissection with emergent surgery as these lesions may evolve and have outcomes similar to those for patients with typical dissections [6]; however, the appropriate treat- 
ment for ascending IMH remains controversial. Most European and North American centers favor a surgical approach, while others have described improvement with medical therapy alone [5]. The European Society of Cardiology Aortic guidelines suggest that a "watchand-wait" conservative strategy that comprises blood pressure control and repeat imaging is reasonable for elderly patients if the aortic size is $<5 \mathrm{~cm}$ and the IMH is $<11 \mathrm{~mm}$ [7]. In general, IMH resolution typically occurs over a period of months; however, the resolution of the IMH in this case occurred much more rapidly than generally reported. Consistent with this report, another group described a similar rapid resolution [9].

The management of acute aortic injuries postTAVR is not well understood [1]. In appropriate surgical candidates, aortic surgery is the standard of care for acute aortic dissections post-TAVR. Some patients may be managed conservatively, but if the dissection extends into the sinuses of Valsalva or if the coronary arteries are involved, then surgery is more clearly indicated [1]. In the case presented, conservative management was deemed most appropriate given the lack of pericardial effusion, the involvement of sinus of Valsalva or coronary arteries and the lack of significant aortic dilation.

\section{Conflict of Interest}

The authors have no conflict of interest relevant to this publication.

\section{Comment on this Article or Ask a Question}

\section{References}

1. Hahn RT, Susheel $K E$, Murat $T$, Martin BL, Samir K, Deepika G, et al. Echocardiographic imaging of procedural complications during balloon-expandable transcatheter aortic valve replacement. JACC CardiovasC Imaging. 2015;8:288-318. DOI: 10.1016/j. jcmg.2014.12.013

2. Nunez-Gil IJ, Bautista D, Cerrato E, Salinas $P$, Varbella $F$, Omede $P$, et al. Incidence, management, and immediate- and longterm outcomes after iatrogenic aortic dissection during diagnostic or interventional coronary procedures. Circulation. 2015;131:2114-2119. DOI: 10.1161/CIRCULATIONAHA.115.015334

3. Januzzi JL, Sabatine MS, Eagle KA, Evangelista A, Bruckman D, Fattori $R$, et al. latrogenic aortic dissection. Am J Cardiol. 2002;89:623-626. DOI: 10.3400/avd. cr.11.00057

4. Barbanti $M$, Yang $T H$, Rodès Cabau J, Tamburino C, Wood DA, Jilaihawi $\mathrm{H}$, et al. Anatomical and procedural features associated with aortic root rupture during balloon-expandable transcatheter aortic valve replacement. Circulation. 2013;128:244-253. DOI: 10.1161/CIRCULATIONAHA.113.002947
5. Harris KM, Braverman AC, Eagle KA, Woznicki EM, Pyeritz RE, Myrmel T, et al. Acute aortic intramural hematoma: an analysis from the International Registry of Acute Aortic Dissection. Circulation. 2012;126:S91-S96. DOI: 10.1161/CIRCULATIONAHA.111.084541

6. Hiratzka LF, Bakris GL, Beckman JA, Bersin RM, Carr VF, Casey DE Jr, et al. 2010 ACCF/ AHA/AATS/ACR/ASA/SCA/SCAI/SIR/STS/ SVM guidelines for the diagnosis and management of patients with Thoracic Aortic Disease: a report of the American College of Cardiology Foundation/American Heart Association Task Force on Practice Guidelines, American Association for Thoracic Surgery, American College of Radiology, American Stroke Association, Society of Cardiovascular Anesthesiologists, Society for Cardiovascular Angiography and Interventions, Society of Interventional Radiology, Society of Thoracic Surgeons, and Society for Vascular Medicine. Circulation. 2010;121:e266-e369. DOI: 10.1161/ CTR.0b013e3181d4739e

7. Erbel R, Aboyans V, Boileau C, Bossone E, Di Bartolomeo R, Eggebrecht $H$, et al. 2014 ESC Guidelines on the diagnosis and treatment of aortic diseases The Task Force for the Diagnosis and Treatment of Aortic Diseases of the European Society of Cardiology. Eur Heart J. 2014;35:2873-2926. DOI: 10.5603/KP.2014.0225

8. Rylski B, Hoffman I, Beyersdorf I, Suedkamp $M$, Siepe M, Nitsch B, et al. latrogenic acute aortic dissection Type A: insight from the German Registry for Acute Aortic Dissection Type A (GERAADA). Eur J Cardiothoracic Surg. 2013;44:353-359. DOI: 10.1093/ ejcts/ezt055

9. Vilacosta I, San Romas J, Ferreiros J, Aragoncillo P, Mendez R, Castillo JA, et al. Natural history and serial morphology of aortic intramural hematoma: A novel variant of aortic dissection. Am Heart J. 1997;134:495-507. DOI: 10.1016/S00028703(97)70087-5

Cite this article as: Thomas TY, Poulose AK, Harris KM. Transient Aortic Intramural Hematoma Complication of Transaortic Valve Replacement. AORTA (Stamford). 2016;4(6):232-234. DOI: http://dx.doi.org/10.12945/j. aorta.2016.16.029 